\title{
Motivated for excellence
}

\author{
By Geraldine W. Kiefer \\ Architectural Writing Consultant \\ Van Dijk, Johnson \& Partners
}

Ursuline College's new Besse Library.

G ood architecture ennobles its site and brings out its singular characteristics. It makes a design statement, yet not so stridently that context-the lay of the land and its particular significance for those who traverse it-is overriden. In fact, today's best designers work for solutions that address contextuality and encourage active, evaluative roles for participants in what may be termed a living theater of architecture. Much contemporary design is termed postmodern as opposed to moderni.e., the ubiquitous white cube or subdividable vertical block of the fifties and sixties. What much postmodernism purports, and what the new Ralph M. Besse Library at Ursuline College exemplifies, is not only an opening up of the cube, a dissolving of design according to solids in favor of design according to screens, but a new theatrical sensibility. For the library, with its limestone screen wall and colonnaded open portico at the apex of the campus quadrangle - each a highly calibrated element that both frames vistas and appears to glide freely in space-functions as a proscenium for the crux of academic life. Van Dijk, Johnson \& Partners, architects for the library, employed a variety of subtle design techniques to blend the building religiously with its neighbors and to seat it comfortably within its site. Contextuality was an absolute prerequisite for the library's active role as presenter and framer.

Master planners for the college campus, sited on 115 magnificent acres in Pepper Pike, a suburban community east of Cleveland, van Dijk, Johnson formulated its classic commons-girding design. Ursuline's quadrangle recalls such hallowed institutions as Cambridge and Oxford universities in Eng- land, and the University of Virginia and Cornell University in the United States. "An acropolis of learning," chief designer and partner Peter van Dijk termed it, situated on the highest promontory of land overlooking the artificial lake that was created to the south. From 1965 to 1974 the firm designed Mullen Academic Building, Dauby Science Center and the Matthew J. O'Brien Campus Center on the crest of the "acropolis," and two dormitories diagonally oppposite them across the lake, with a network of brick and stone walkways and low stone retaining walls interconnecting them. The buildings were designed and constructed in what is now known as the "Ursuline Blend" of brick, a buff-colored, nubby textural masonry that has a savvy rusticity about it. Limestone trim and coping, slate window sills and varnished oak doors and portico soffits complete the exterior palette.

The new library, nestled into the rise that reaches to the north contour of the campus, utilizes the same materials: Ursuline Blend brick for the main building block and the lantern piers that announce it from the quadrangle, red oak window and door frames, the limestone entrance wall, slate sills and threshholds. While functioning as elements of the library grid, the various building components-terrace, portico, entrance hall and the stepped volumes behind, scale themselves securely to their neighbors and continue their carefully stepped and opened profiles.

Most importantly, the library now provides an apex for the campus quadrangle that it lacked before, a locus for learning that fulfills the directive expressed by college President Sister M. Kenan that the library be "the heart of the campus." 


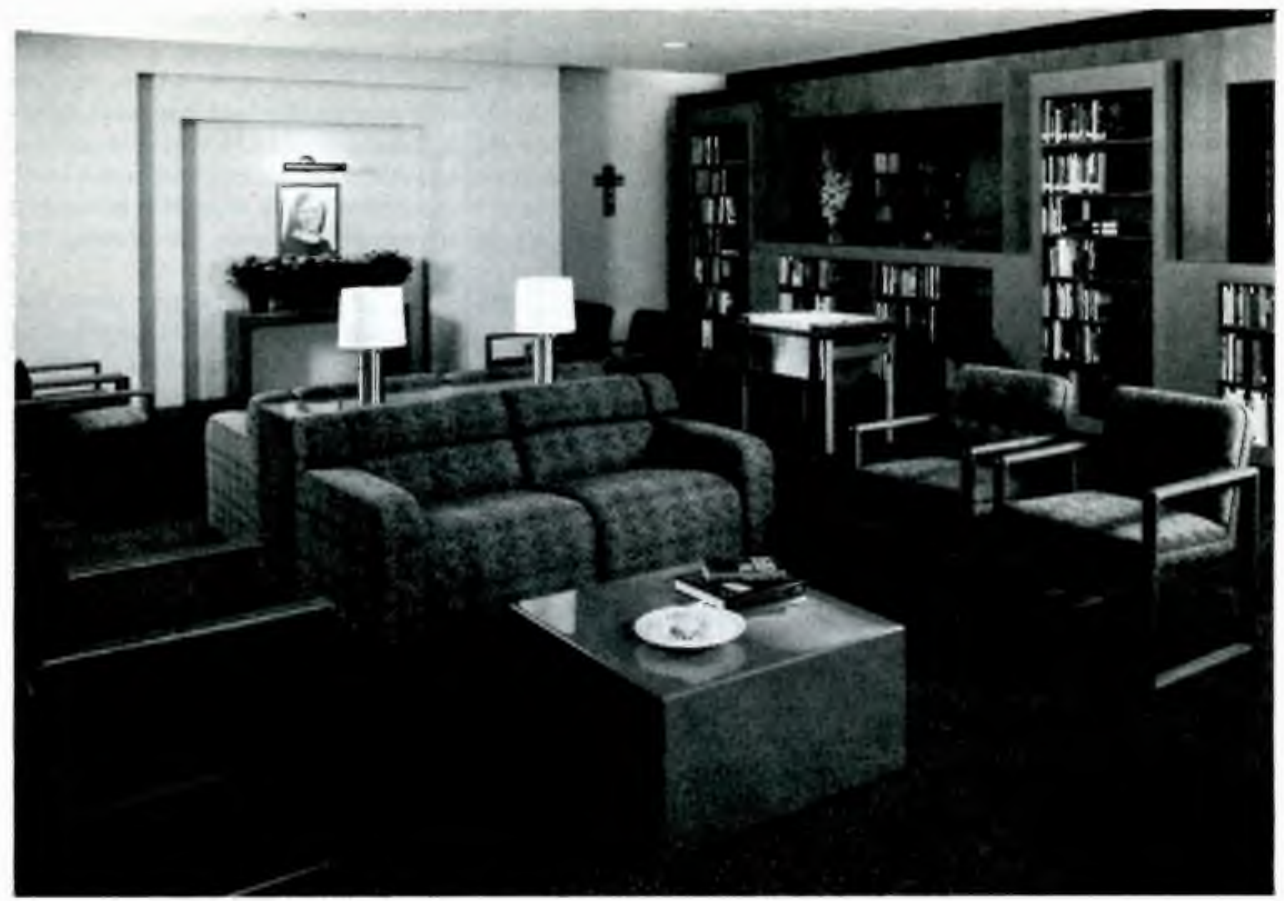

The Sister Dorothy Kazel reference collection and lounge, near the Library entrance.

The planning process for a separate library facility began in the late 1970 s, when it was evident that two floors in the student center could neither adequately display nor store 60,000 volumes, and that an evolving non-print technology would require a comprehensive media center. In addition, ACRL's 1975 Standards for College Libraries recommended a minimum of 112,000 print volumes for a college the size of Ursuline. After detailed study and a 3-year total campus reevaluation, it was determined that a new library with approximately double the amount of space of the existing 11,300 square foot facility was needed. Thanks to successful fund-raising efforts in the community, engineered by a blue-ribbon steering committee composed of long-standing Ursuline patrons, (among whom was Ralph M. Besse, who almost singlehandedly raised the funds that livilt the first buildings on the Pepper Pike campus), the college was able to plan for a building triple the size of the existing library that would incorporate a state of the art media center as an integral component in its functioning.

Critical to this functioning were contiguous spaces for administrative services, namely circulation with reserve book control, current and bound periodical referencing, acquisition and cataloging. These procedures are the core of any college library, particularly one specializing in up-to-theminute technical data (Ursuline's bachelor of science in nursing program is targeted for registered nurses throughout Cuyahoga County as well as nursing students). However, Ursuline was recently the recipient of a $\$ 150,000$ Challenge Grant from the National Endowment for the Humanitiesmatched 3 to 1 - for the acquisition of print and non-print materials. With new materials coming in (the collection now numbers some 95,000 print volumes alone), and concurrently with new prospects for automation (Ursuline is one of several regional libraries testing a new Regional Bibliographic Database of the Cleveland Area Metropolitan Library System-CAMLS - this fall), Ursuline's staff/technical capability had to be geared to the most efficient, smoothly interacting spaces possible.

Accordingly, the architects planned from the inside out. Books arrive at an existing loading dock at the lower level of the science building, then are transported through a receiving corridor-which can also serve as a temporary holding area - to the elevator in the new building, thence up one floor to the staff entrance corridor which terminates at the acquisitions secretary's office. 620 square feet of technical services at the core of the staff area provide four work positions and extensive shelving capability, and services for OCLC terminals.

Wrapped around Technical Services in a reversed-L configuration are periodical services and circulation. Responsible for accessing over 500 titles in the library alone (many others are available through DIALOG), the serials librarian and 
two assistants maintain unobstructed visual control over the periodicals section and physical control of current periodicals, which are shelved on both sides of the freestanding unit behind their desk. Just a few steps away via a passage lined with supply cabinets and provided with a niche for truck storage is the circulation area. It is likewise designed for total visual control over its purview, which includes the main entrance, stairway to the basement and second floor, first floor reference and special collections, card catalog and reference librarian. Reserve books are located behind the circulation desk, in full view of students and patrons and accessible directly by the staff.

Both the main circulation desk and the media center circulation desk were custom designed for their particular needs, including specialized storage areas, work surfaces including typing areas, and internal bulletin display. Again for secure staff access, the non-print volumes in the media center (programmed for 3,600 ) are located behind the circulation desk but in full view of library patrons. Faculty and students enter the media center through its own lounge and reference section which displays current media catalogs and locator guides. Both hardware, stored in an extensive storage/repair facility behind the circulation desk, and software can be checked out for use in classrooms or can be used in the several specialized technical rooms located in the center itself: TV production, editing/duplicating, graphics production and viewing rooms. The main study room, carefully sited to incorporate soft natural light from the north, incorporates student media carrels with VCRs, slide tape machines and audio cassette recorder/players. It is the college's desire that the most current technical systems and software be available to the students and faculty, not just for communications arts study, but to access up-tothe-minute data in the career-related fields serviced by Ursuline's faculty: nursing, women in management, art therapy, music business and education.

The library's print holdings-130,000 at capacity (in the future an additional 100,000 might be stored on compact shelving in 5,000 square feet of programmable space at the basement level)occupy the first and second floors. Bound periodicals and the reference collection are housed on the first, circulating books and the education department's curriculum library, on the second. The architects worked closely with their mechanical and electrical engineering consultants. to ensure that the work and research environment be of optimum quality.

Lighting was designed perpendicular to the stacks. Nine-cell fluorescent fixtures engineered for maximum coverage and minimum brightness at the source illuminate the stacks to the lowest level. Bi-level switching with up-and-down positioning of the bulbs permits a consistent level of illumination at all times. Since study carrels and individual and group study rooms at the perimeter of the partition-free stack areas are ringed on the north and east elevations by $6^{\prime}-4^{\prime \prime} \times 4^{\prime}-8^{\prime \prime}$ windows with adjustable blinds, energy-efficient low level lighting is preferable during the day. A variable volume air conditioning system provides a consistent level of coolness; the amount of air supplied, however, varies according to need, thereby facilitating energy conservation.

Ursuline's former library had no provisions for lounges. In keeping with their traditional practice of honoring benefactors and prominent religious leaders, the Ursuline nuns programmed three dedicatory lounges for the new space, each to reflect in texture, lighting and color the person whose memory it was deemed so important to share.

For the Sister Dorothy Kazel lounge, prominently placed just inside the main entrance, the architects and their interior designer had a particularly challenging task. Sister Dorothy, one of the nuns martyred in El Salvador in 1980 while serving with the Cleveland Diocesan Mission Team, was to be memorialized not just with a seating space, but with a living memorial, a new research center for Global Awareness of Peace and Justice Issues. The Kazel collection will assist both scholarly and active pursuits in the field of international relations. Peter van Dijk, project architect Paul Westlake Jr., and the firm's interiors specialist Susan Plachy designed the room with a festive, South American atmosphere, in tangerines with accents of yellow and blue-green. Furnishings are classically modern, comfortable, and since they are meant to be used constantly, durable. Gently lit by fluorescent uplights concealed above a lowered ceiling, the Sister Dorothy lounge has a self-containing presence. Yet its conceptual connection to the rest of the library as a specialized yet integrated center of learning is stressed by the ingeniously designed bookshelf/screen wall that establishes its parameters and orients it to the rest of the space. A sculptural solution of interpenetrating cubic planes, volumes and openings similar in feeling to the limestone screen wall whose interior face is visible just outside the windows of the lounge, the bookshelf screen likewise acts as a staging presence as it sets off the books and subtly acquiesces to their importance.

The two lounges on the second floor, the Louise E. Mellen Lounge adjacent to and interconnected with the library's extensive nursing collection, and the Mother Marie Sands Lounge, dedicated to the former General Superior and college president, were exquisitely fine-tuned to be unique characterizations. Mrs. Mellen's devoutness and exquisite femininity were expressed in soft lines and delicate colorations. Mother Marie's prominence, leadership and sensitivity (she loved living things and just a touch of yellow) found form in a room that commands the best panoramic view from the facility. At the same time, in its rich blue furnishings, carpet and indirect cove lighting, this main reading lounge unfolds a delicate, self-containing and med- 


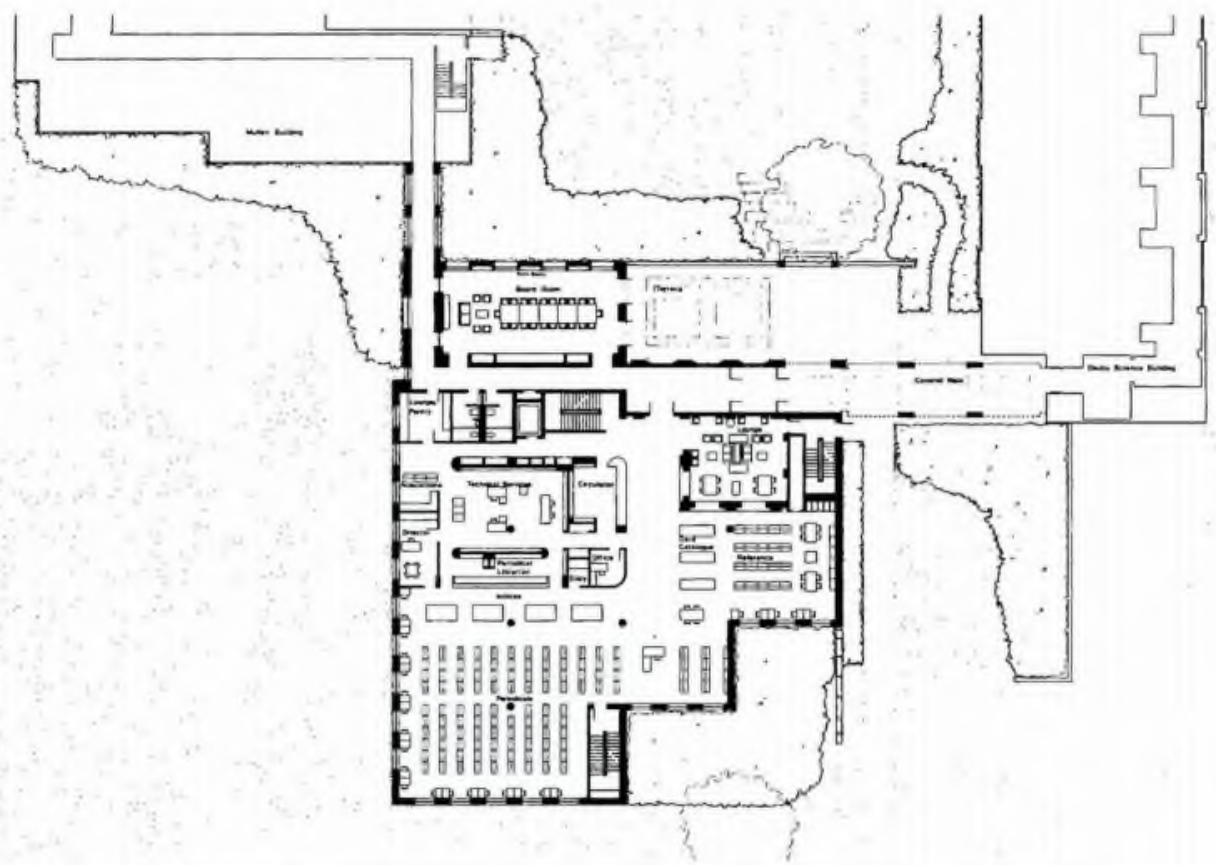

First floor plan of the Ralph M. Besse Library, Ursuline College, designed by van Dijk, Johnson \& Partners, Cleveland.

itative presence like an opening flower.

Through substantial donations over the years, Ursuline has amassed a fine stamp and rare book collection that are not only research tools, but catalysts for ongoing donations (Ralph Besse, for example, the executive and education benefactor for whom the library is named, has donated his collection of general non-fiction and river books). As the Ursuline nuns conceived their new library to be the central research center of their campus, it was appropriate that these collections be carefully housed there. Approached via the corridor that accesses the Mother Marie Lounge and continues to an outdoor cedar-decked terrace, the stamp collection emerges as an ongoing display in six inset cases, lit solely by incandescent downlights to preserve delicate color and detail. Likewise incandescent-lit is the stamp room itself which features a custom designed folio display cabinet extending the entire width of the space.

Appropriateness to function always is the ultimate criterion for a building's success. For a library, each space works as it serves to encourage study, reflection and excellence. Although challenged to vary their solutions for the many specialized spaces required in Ursuline's facility, van Dijk and his team had a unique opportunity in what might be termed its culminating space, the Sister Gonzaga Haessly Room, named for the Dean of Ursuline from 1932 to 1966 . A Board room and reception facility for distinguished guests, graduates and other college honorees, and the repository for Ursuline's rare books, the Haessly Room was to be the heart of the library. Quiet, distinguished, distinctly clad and quintessentially formal, yet close to the outside world, it was to personify the intent of Ursuline's mission statement, to prepare students for active, caring roles in the community by immersion in an academic environment activated by formal precept and personal example.

Thus, the architects placed the Haessly Room in front of the library proper and opened its French doors to the building's open-air conversational terrace. Within the space formality is clasped within a tight grid that divides, then subdivides each elevation. The governing material is oiled red oak exquisitely worked into reverse diamond patterns on wall cabinets and the custom designed, bronzeframed tables (which can be moved for various seating arrangements and functions). The rare books, enclosed but visible within protective, ornamental bronze grilles, evoke the excellence by precept that has motivated Ursuline's patrons to support it since its founding in 1871.

That the library is not only the heart of the campus, but its main artery, is realized in its function as the missing link in the quadrangle's internal corridor system. Peter van Dijk, long-time advocate for covered connectors and pedestrian linkages in northern climates, took special care to link Mullen Academic Building to Dauby Science Center via the new library, and to make the three-building complex completely handicapped accessible on the ground floor level. Initial research revealed but a 4 -inch difference in the ground floor levels of Dauby and Mullen, but the Mullen corridor 
dropped down three stairs at its northwest, library access end. Van Dijk eliminated those steps, raised the floor level to that of Dauby and the in-process library, and connected all three buildings, as well as the Haessly Room, by means of a covered entrance passage. (A gentle brick ramp leads from this passage to the quadrangle's sidewalk network.) He effected a spine outwards from which Ursuline's academic buildings branch with a singular rationality and grace.
The Ralph M. Besse Library, designed for Ursuline College, will in no way be an insular facility. According to library director Juanita Weisel, its raison d'etre is first to serve Ursuline faculty and students and secondly people from surrounding communities. Housed in a facility that itself is a product of learned and creative excellence, it assumes a stellar role in the Greater Cleveland library community.

\section{Baltimore '86}

\section{Alan C. Kay, the Father of the Personal Computer, to be theme speaker in Baltimore.}

$\mathbf{E}$ Fourth National Conference, April 9-12, 1986, in Baltimore. On Wednesday, April 9, at 1:00 p.m., Alan C. Kay will make the first theme presentation concerning his perspective on technological changes, personal computing, and artificial intelligence. He will utilize a variety of equipment, including laser disks, to generate and project messages illustrating his thoughts.

The following background information has

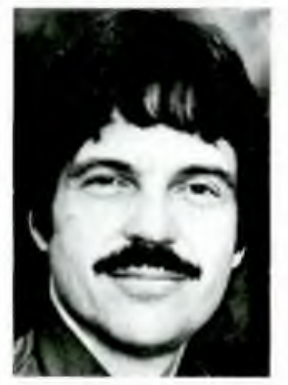

Alan C. Kay been supplied by Kay's office at Apple Computer. "Father of the personal computer" is a title Alan C. Kay disclaims, but many acknowledge that it was Kay's ideas which succeeded in getting industry's attention for the personal computer.

Much of this attention resulted from work done at the Xerox Palo Alto Research Center (PARC) whose alumni are responsible for much of the cur- rent leading-edge computer technology. The Golden Age of PARC occurred between 1971 and 1976, when Xerox gave a blank check to a group of young and talented computer scientists in a creative think tank environment. It was here that Kay conceived of Dynabook, the powerful lap-sized personal computer of the 1980 s that would allow people to draw and write anywhere. Dynabook was the inspiration for Alto, the forerunner of Macintosh. Another particularly celebrated contribution was Smalltalk, a very high-level objectoriented programming language used by non-programmers. He pioneered the use of icons instead of typed words for telling computers what to do next.

During his time at PARC, Kay encouraged children to visit and work with him, as he pledged never to design a personal computer that couldn't be used by a child. He explains, "I think that since children appear to have to construct the world inside of their heads in order to become human beings, then people must be natural constructors. Computers are the best construction material that we have ever come up with outside our own brains."

The son of a physiologist and artist/musician, 